\title{
Bovine trypanosomosis: A threat to cattle production in Chena district, Southwest Ethiopia
}

\author{
Bizuayehu Alemayehu ${ }^{1}$ Basaznew Bogale ${ }^{1}$, Tewodros Fentahun $^{2}$, Mersha Chanie $^{1}$ \\ ${ }^{1}$ Departement of Veterinary Paraclinical Studies, Faculty of Veterinary Medicine, University of Gondar, Gondar, Ethiopia; \\ kcchou@gordonlifescience.org \\ ${ }^{2}$ Departement of Basic Veterinary Science, Faculty of Veterinary Medicine, University of Gondar, Gondar, Ethiopia
}

Received 21 August 2012; revised 23 September 2012; accepted 30 September 2012

\section{ABSTRACT}

A cross-sectional study to determine the prevalence of bovine trypanosomosis was carried out in Chena district, Kefa zone, southwest Ethiopia from September 2010 to January 2011. Blood samples were collected from 391 randomly selected local (zebu) breed cattle in three representative peasant associations (PAs). The buffy coat and Giemsa stained thin blood films examination techniques were used for parasite detection and identification. The packed cell volume (PCV) estimation was also conducted. From a total of 391 cattle, $6.9 \%(n=27)$ of the animals were found positive for trypanosome infection. The trypanosome species observed across the study animals were $T$. congolense (4.89\%), T. vivax (1.54\%), and T. b. brucei $(0.51 \%)$ as single infections. The infection rate of $T$. congolense and $T$. b. brucei varied significantly $(P<0.05)$. The statistical analysis revealed that no significant difference $(P>0.05)$ in infection rate was found between male $(7.79 \%)$ and female $(5.62 \%)$ animals. The prevalence was $2.24 \%$ and $8.29 \%$ in young and adult cattle, respectively with significant difference $(P<0.05)$ between them. The prevalence rate in good, medium and poor body conditioned animals were $7.28 \%$, $0.78 \%$ and $13.39 \%$, respectively with a statistical significant difference $(P<0.05)$ among them. The mean PCV of the infected animals (17.56\%) appeared significantly $(P<0.05)$ lower than the non-infected (25.4\%). Even if, the present study indicated a low prevalence of bovine trypanosomosis in the study areas, its impact on production and potential transmission to others should not be neglected.

Keywords: Bovine; Buffy Coat; Chena; PCV; Prevalence; Trypanosomosis

\section{INTRODUCTION}

Domestic livestock in Africa are important as a source of protein (milk and meat) to humans, animal traction, income (hides) and investment (social security) and manure for enhancing agricultural (crop) production [1]. Bovine trypanosomosis, an important protozoan disease caused by the genus Trypanosoma is transmitted through bites by different species of Glossina and mechanically by a number of biting flies such as Tabanus and Stomoxys spp. [2]. Tsetse transmitted African typanosomosis is found between latitude $14^{\circ} \mathrm{N}$ and $29^{\circ} \mathrm{S}$ covering across over 37 countries in Africa [3]. It is estimated that 60 million people and 48 million cattle are at risk of contracting African trypanosomiases [4].

Bovine trypanosomosis and its vectors (Glossina species) occur in vast areas of the sub-Saharan Africa with devastating impact on livestock productivity posing a serious threat to the lives and livelihood of entire communities and constitute the greatest single constraint to livestock and crop production thereby directly contributing to hunger, poverty, protein malnutrition and suffering of entire communities in Africa [5].

Africa trypanosomiasis is responsible for 3 million livestock and 55,000 people death annually in agriculture and mixed farming [3,6]. Africa looses over 3 million cattle and other domestic livestock through deaths caused by trypanosomosis every year [1]. The effect of trypanosomosis is not only the direct losses but also due to the indirect losses, which includes exclusion of livestock and animal power based on crop production in the overall stocked and degraded high lands as consequences of imbalance land use brought about the presence of tsetse flies and the disease trypnosomosis in low land [7].

According to Langridge [8] the tsetse flies in Ethiopia are confined to the southern and western regions between longitudes $33^{\circ} \mathrm{E}$ and $38^{\circ} \mathrm{E}$ and latitude $5^{\circ} \mathrm{N}$ and $12^{\circ} \mathrm{N}$. They infest areas which together amount to $97,855 \mathrm{~km}^{2}$ (8.1\% of the land area). Tsetse infested areas lie in the lowlands and also in the river valleys of Abay (Blue Nile), 
Baro, Akobo, Didessa, Ghibe and Omo.

The most important trypanosome species affecting cattle in Ethiopia are $T$. congolense, $T$. vivax and T. brucei. Trypanosomosis in cattle locally referred, as "Gendi" is a serious constraint to livestock production in areas of the north and southwest Ethiopia at an altitude of below 2000 m.a.s.l [9]. Although bovine trypanosomosis is considered an important livestock disease in Ethiopia, there is no information in the literature about the disease situation in the study area. Therefore, the objective of the current study was to determine the prevalence of bovine tryponosomosis and associated risk factors in the study area.

\section{MATERIAL AND METHODS}

\subsection{Study Area}

A cross-sectional study was conducted from September 2010 to January 2011 to determine the prevalence of bovine trypanosomosis in Chena district, Kefa zone, southwest Ethiopia in three randomly selected peasant associations (PAs) (Gawetata, Buba, and Boba Bela). The mean annual rainfall of the district ranges between 1284 - $1780 \mathrm{~mm}$ and covered with different types of vegetations. The livestock population of the district is estimated as cattle 103,479, sheep 51,234, goat 17,372, horse 4169, mule 1109 donkey 34 and poultry 133,059 [10].

\subsection{Study Population}

The study animals were local breed cattle (231 males and 160 females) kept under small holder extensive management system in the study area. The age of animals was estimated following description of [11] for Zebu cattle. Conventional age categories were made as young (1 - 3 years), and adult ( $>3$ years). Body condition scores were estimated as per the recommendations of Nicholson and Butterworth [12] for evaluating the body condition of zebu cattle. The body condition of animals was recorded by classifying animals in to three groups as good, medium, and poor based on the appearance of ribs and dorsal spines.

\subsection{Study Design}

A cross-sectional study design was used to determine the prevalence of bovine trypanosomosis. A simple random sampling and purposive sampling methods were followed to select the study animals and study sites, respectively. The sample size was determined based on the expected prevalence of $50 \%$ and absolute desired precision of $5 \%$ at $95 \%$ confidence level. The desired sample size was calculated using the standard formula described by Thrusfield [13].

\subsection{Parasitological Study}

A total of 391 blood samples were collected from jugular veins of cattle by sterile sharp needle. Samples were collected in clean and dry test tube containing EDTA as anticoagulant for blood smear. During blood collection the necessary bio-data of each animal was recorded. The Buffy coat technique using phase contrast microscope was used for the detection of trypanosomes in the blood. Species identification was done by morphological examination of trypanosomes on Giemsa stained thin blood smears prepared from the positive animals and examined under a microscope using the oil immersion $100 \times$ objectives [14].

\subsection{Haematological Examination}

Blood samples for PCV were collected from parasitaemic and aparasitaemic animals using heparinized haemotocrit capillary tubes. The capillary blood was centrifuged using microhaematocrit centrifuge and PCV of each animal was measured using a microhaematocrit reader following the standard procedure described by Murray et al. [14].

\subsection{Data Analysis}

Data on individual animals and parasitological examination results was inserted into Ms-excel spread sheet program to create a data base and transferred to the SPSS soft ware version 17.0 program of the computer before analysis. Chi-square was employed to determine prevalence on sex, age and body condition basis. Two sample t-tests were utilized to compare the mean PCV values of the parasitaemic and aparasitaemic animals. Differences between parameters were tested for significance at probability levels of 0.05 or less.

\section{RESULTS AND DISCUSSION}

\subsection{Parasitological Findings}

A total of 27 samples of the 391 blood samples examined were positive for trypanosome infections, representing $6.9 \%$ prevalence. The infection rate of trypanosomosis was $14.41 \%(n=16), 5.43 \%(n=10)$ and $1.04 \%$ ( $\mathrm{n}=1$ ) for Gawetata, Buba, and Boba Bela PAs, respectively with a significant difference $(\mathrm{P}<0.05)$ between them (Table 1). In assessing the type of trypanosomes species observed across the study animals revealed that of the $6.9 \%$ positive cattle examined, $4.89 \%$ were positive for $T$. congolense, $1.54 \%$, for $T$. vivax and $0.51 \%$ for T. b. brucei.

The prevalence of trypanosome infection was higher for male (8.65\%) than for female (4.37\%) animals. However, statistical significant difference $(\mathrm{P}>0.05)$ was 
not observed between sexes. The infection rate of trypanosomosis was $3.37 \%$ and $7.94 \%$ in young and adult cattle, respectively with a statistical significant difference $(\mathrm{P}<0.05)$ among age groups (Table 2$)$. With respect to body condition score, the prevalence was $1.56 \%, 3.97 \%$ and $16.96 \%$, in good, medium and poor score, respectively with a significant variation $(\mathrm{P}<0.05)$ between them (Table 2).

\subsection{Hematological Findings}

The PCV value of all examined cattle ranges from $10 \%$ to $39 \%$. The mean PCV of the infected (17.56\%) appeared significantly $(\mathrm{P}<0.05)$ lower than the mean PCV of non-infected (25.4\%) animals.

The present study had shown the overall prevalence of trypanosomosis in the study area was $6.9 \%$. This result was lower than the report of Mekuria and Gadissa [15] (12.42\%) in Metekel and Awi zones of northwest Ethio- pia. Variations in prevalence rate had been recorded among studied sites. The high prevalence of the disease especially at Gawetata and Buba PAs could be due to the presence of suitable habitat for the vectors which results in high fly density. From the study of Leak et al. [16], it was indicated that variation in tsetse density appeared to be the main factor for variation in the prevalence of trypanosomosis.

Information from distribution of infection by species of trypanosomes showed that infection due to T. congolense was highest in all studied PAs followed by $T$. vivax and least by $T$. b. brucei. The predominance of T. congolense infection in cattle may be due to the high number of serodemes of $T$. congolense as compared with $T$. vivax and the development of better immune response to $T$. vivax by the infected animal [16]. Likewise, Mekuria and Gadissa [15] reported similar species of trypanosomes with a high prevalence in Metekel and Awi zones of northwest Ethiopia.

Table 1. Trypanosome species identified based on study sites.

\begin{tabular}{|c|c|c|c|c|c|c|c|c|}
\hline \multirow[t]{2}{*}{ PAs } & \multirow[t]{2}{*}{ No. examined animals } & \multirow[t]{2}{*}{ No. infected animals } & \multicolumn{3}{|c|}{ Trypanosomes detected } & \multirow[t]{2}{*}{ Prevalence (\%) } & \multirow[t]{2}{*}{$\chi^{2}$} & \multirow[t]{2}{*}{ P-value } \\
\hline & & & T.c & T.v & T.b.b. & & & \\
\hline Buba & 184 & 10 & 6 & 2 & 2 & 5.43 & & 0.05 \\
\hline Gawetaa & 111 & 16 & 12 & 4 & - & 14.41 & & \\
\hline BobaBela & 96 & 1 & 1 & - & - & 1.04 & & \\
\hline Total & 391 & 27 & 19 & 6 & $2(0.51 \%)$ & 6.96 & & \\
\hline
\end{tabular}

$T . c=T$. congolense, $T . v=T$. vivax, T. b.b. $=$ T. brucei brucei.

Table 2. The prevalence of trypanosomosis based on different risk factors.

\begin{tabular}{|c|c|c|c|c|c|}
\hline Risk factors & No. examined animals & No. positive animals & Prevalence (\%) & $\chi^{2}$ & P-value \\
\hline \multicolumn{6}{|l|}{ Sex } \\
\hline Male & 231 & 20 & 8.65 & \multirow{3}{*}{2.727} & \multirow{3}{*}{0.256} \\
\hline Female & 160 & 7 & 4.37 & & \\
\hline Total & 391 & 27 & 6.9 & & \\
\hline \multicolumn{6}{|l|}{ Age } \\
\hline Young ( $<3$ years) & 89 & 3 & 3.37 & \multirow{3}{*}{21.289} & \multirow{3}{*}{0.019} \\
\hline Adult (>3 years) & 302 & 24 & 7.94 & & \\
\hline Total & 391 & 27 & 6.9 & & \\
\hline \multicolumn{6}{|l|}{ Body condition score } \\
\hline Good & 128 & 2 & 1.56 & \multirow{4}{*}{26.838} & \multirow{4}{*}{0.000} \\
\hline Medium & 151 & 6 & 3.97 & & \\
\hline Poor & 112 & 19 & 16.96 & & \\
\hline Total & 391 & 27 & 6.9 & & \\
\hline
\end{tabular}


A higher infection rate was observed in adults than in young groups. The lower prevalence in young animals compared to adults can be attributed to restricted grazing of young animals which tends to reduce their chance of contact with the vectors of these disease. Rowlands et al. [17], in Ghibe valley indicated that suckling calves do not go out with their dams but graze at homesteads until they are weaned off. According to Torr et al. [18] tsetse flies are attracted significantly more by odor of large animals and animals that showed less defensive behavior and least by calves. Daya and Abebe [19] have shown an effect of age on the prevalence of trypanosome infections in cattle where calves are the least infected. The low prevalence and incidence of trypanosome infections in calves has also been attributed to the protective effect of maternal immunity that does not prevent calves from becoming infected but mitigates the adverse effect of such an infection by reducing the parasitemia to a very low, almost undetectable level [20].

Though sex prevalence rates revealed a slightly higher percentage among the males, statistically there was no significant difference in the prevalence rates. Daya and Abebe [19] also reported similar results where they observed no significant difference in trypanosome infection between males and females. Onyiah [21] and Quadeer et al. [22], in separate studies added that no statistically significant difference in the prevalence rates of cattle by sex. Therefore, they have equal chance of coming in contact with the flies and eventually with the disease. In contrast to this, Magona et al. [23] reported that males had a significant higher prevalence of trypanosomosis than females.

Animals with poor body condition were more associated with the disease as compared with animals in good body condition. Trypanosomosis causes weight loss (cachexia), and emaciation is a characteristic sign of trypanosomosis [24,25].

Regarding the PCV determination (even though other disease contribute to the low PCV values), most of the parasitemic animals were found to be anaemic compared with aparasitemic animals and the difference was significant. Such significant difference of PCV values in infected and non-infected cattle had been reported by several workers [26-28]. They demonstrated that haematocrit values of infected cattle decreased during the infection period. This indicated that among others the notable pathogenic effects of mechanically and biologically transmitted trypanosomosis. Therefore, trypanosomosis may be involved in adversely lowering the PCV value of infected animals.

\section{ACKNOWLEDGEMENTS}

We would like to express our thanks to the Faculty of Veterinary Medicine for financing this research project and all the technical staff members of this faculty for their diligent help.

\section{REFERENCES}

[1] FAO (2005) The influence of trypanosomosis on African animal production. Animal Zootechnica, 1-2.

[2] Oluwafemi, R.A., Ilemobade, A.A. and Laseinde, E.A.O. (2007) The Impact of African animal trypanosomosis and tsetse on the livelihood and wellbeing of cattle and their owners in the BICOT study area of Nigeria. Scientific Research and Essays, 2, 380-383.

[3] Mulumba, K. (2003) Socio-economic and agricultural factors in the research and control of trypanosomiasis. PAAT Technical and Scientific Series, 4. FAO. Rome.

[4] Kristjason, P.M., Swallow, B.M., Rowland, G.J., Kruska, R.L. and Delew, P.P. (1999) Measuring the cost of African animal trypanosomiasis the potential benefit of control and returns to research. Agricultural System, 59, 79-98. doi:10.1016/S0308-521X(98)00086-9

[5] PATTEC (2002) Proceedings for Pan African Tsetse and Trypanosomosis Eradication Campaign.

[6] Abenga, J.N., Ewenzor, F.N.C., Lawani, F.A.G., Ezebuiro, C. Sule, J. and David, K.M. (2002) Prevalence of trypanosomiasis in trade cattle at slaughter in Kaduna State, Nigeria. Journal of Parasitology, 23, 107-110.

[7] Awoke, K. (2000) Study of trypanosomoses and its vectors in Humbo and Merb woredas. Biology, hosts and geographic distribution. Journal of Ethiopian Veterinary Association, 1, 181-290.

[8] Langridge, W.P. (1976) A tsetse and trypanosomiasis survey of Ethiopia. Addis Ababa, Ethiopia, Ministry of Overseas Development of British and Ministry of Agriculture of Ethiopia, 97.

[9] Getachew, A. (2005) Review article trypanasomiasis in Ethiopia. Journal of Biological Science, 27, 1-8.

[10] CWAO (2010) Chena Worda Agricultural office annual report, 12-19.

[11] FAO (1983) Mnual for animal health auxiliary personel. Rome, 117-129.

[12] Nicholson, M.J. and Butterworth, M.H. (1986) A guide to condition scoring of zebu cattle. ILCA, Addis Ababa Ethiopia, 212-235.

[13] Thrusfield, M. (2005) Veterinary epidemiology. 2nd Edition, Blackwell Science, Oxford, 117-198.

[14] Murray, M., Murray, P.K. and McIntyre, W.I.M. (1988) An improved parasitological technique for the diagnosis of African trypanomiasis. Transaction of the Royal Society of Tropical Medicine and Hygien, 71, 325-326. doi:10.1016/0035-9203(77)90110-9

[15] Mekuria, S. and Gadissa, F. (2011) Survey on bovine trypanosomosis and its vector in Metekel and Awi zones of Northwest Ethiopia. Acta Tropica, 117, 146-151. doi:10.1016/j.actatropica.2010.11.009

[16] Leak, S.G.A., Mulatu, W., Authie, E., D’Ieteren, G.D.M., Peregrine, A.S., Rowland, G.J. and Trail, J.C.M. (1993) Epidemiology of bovine trypanosomiasis in the Gibe val- 
ley, Southern Ethiopia. Tsetse challenge and its relationship to trypanosome prevalence in cattle. Acta Tropica, 53, 1221-1234. doi:10.1016/0001-706X(93)90024-6

[17] Rowlands, G.J., Mulatu, W., Authie, E., Leak, S.G.A. and Peregrine, A.S. (1995) Epidemiology of bovine trypanosomosis in the Ghibe Valley, South-west Ethiopia. Acta Tropica, 53, 135-150. doi:10.1016/0001-706X(93)90025-7

[18] Torr, S.J. and Mangwiro, T.N.C. (2000) Interactions between cattle and biting flies: Effects on the feeding rate of tsetse. Medical and Veterinary Entomology, 14, 400-409. doi:10.1046/j.1365-2915.2000.00257.x

[19] Daya, T. and Abebe, G. (2008) Seasonal dynamics of tsetse and trypanosomosis in selected sites of southern nation, nationalities and peoples regional state, Ethiopia. Ethiopian Veterinary Journal, 12, 77-92.

[20] Fiennes, R. (1970) Pathogenesis and pathology of animal trypanosomiasis, In: Mulligan, H.W., Ed., The African Trypanosomiasis, Allen and Unwin, London, 729-750.

[21] Onyiah, J.A. (1997) African animal trypanosomosis, an overview of the current status in Nigeria. Tropical Veteterinary Journal, 15, 1-16.

[22] Quadeer, M.A, Danbirni, S., Usman, M., Akogun, O.B., Gundiri, M.A. and Bobbo, A.G. (2008) Prevalence of bovine trypanosomosis in Bassa local government area,
Plateau State, Nigeria. Nigeria Journal of Parasitology, 29, 136-139.

[23] Magona, J.W., Walubengo, J. and Origin, J.T. (2008) Acute haemorrhagic syndrome of bovine trypanosomosis in Uganda. Acta Tropica, 107, 186-191. doi:10.1016/j.actatropica.2008.05.019

[24] Urquhart, G.M., Armour, J., Duncan, J.L, Dunn, A.M. and Jennings, F.W. (1996) Veterinary parasitology. 2nd Edition, Blackwell Science, Oxford, 212-230.

[25] FAO (2002) Food, agriculture and food security: The global dimension. WFSO 2/Tech/Advance unedited version. FAO, Rome, 19-28.

[26] Murray, M. and Dexter, T.M. (1988) Anemia in bovine African trypanosomosis. Acta Tropica, 45, 389-432.

[27] Marcotty, T., Simukoko, H., Berkvens, D., Vercruysse, J., Praet, N. and Van den Bossche, P. (2008). The use of the PCV-value in the diagnosis of trypanosomal infections in cattle. Preventive Veterinary Medicine, 87, 288-330. doi:10.1016/j.prevetmed.2008.05.002

[28] Vanden Bossche, P. and Rowlands, G.J. (2001) The relationship between the Parasitological prevalence of trypanosomal infection in cattle and herd Average packed cell volume. Acta Tropica, 78, 163-170. doi:10.1016/S0001-706X(00)00182-0 